\title{
Oxygen Free Radicals and the Cerebral Arteriolar Response to Group B Streptococci
}

\author{
ALICE A. MCKNIGHT, WILLIAM G. KEYES, MARK L. HUDAK, AND M. DOUGLAS JONES, JR.
}

Departments of Pediatrics (Eudowood Neonatal Pulmonary Division), Gynecology and Obstetrics, and Anesthesiology/Critical Care Medicine, The Johns Hopkins Hospital, Baltimore, Maryland 21205 and Departments of Pediatrics, The University of Colorado School of Medicine and The Children's Hospital, Denver, Colorado 80218

\begin{abstract}
We used a cranial window preparation to observe the effects of direct application of group B streptococci to the surface of the brain in the adult rat. Continuous exposure to group B streptococci at concentrations of $10^{3}$ and $10^{5}$ organisms $/ \mathrm{mL}$ caused progressive dilation of surface (pial) cerebral arterioles that became statistically significant $(p<0.05)$ after $2.5 \mathrm{~h}$. These results were reproduced with heat-killed organisms at the same concentration, but not with a bacteria-free filtrate of the growth medium. In separate studies, we found that infusion of alkaline cerebrospinal fluid $(\mathrm{pH}=7.8$ ) into the window did not reverse vasodilation, suggesting that it was not due to progressive cerebrospinal fluid acidosis. A solution of nitroblue tetrazolium infused into the window at the end of a 3-h exposure to the organism was promptly reduced, suggesting the presence of oxygen free radicals. Treatment with i.v. polyethylene glycol-superoxide dismutase and polyethylene glycol-catalase in doses of 10000 and $20000 \mathrm{U} /$ $\mathrm{kg}$, respectively, was itself without effect on pial arterioles, but treatment with these compounds before exposure to group B streptococci eliminated the vasodilation. These data support a role for oxygen free radicals in the pathogenesis of pial arteriolar dysfunction induced by exposure to group B streptococci. (Pediatr Res 31: 640-644, 1992)
\end{abstract}

Abbreviations

CSF, cerebrospinal fluid

PEG, polyethylene glycol

SOD, superoxide dismutase

The late pathologic effects of meningitis are well documented $(1,2)$, but much less is known about the early effects of bacterial contamination of the CSF. Preliminary data from our laboratory indicate that application of group B streptococci to the surface of the brain causes dilation of surface, or pial, arterioles (3). This is consistent with observations recently published by Pfister et al. (4) showing hyperemia of the superficial cerebral cortex as early as $1 \mathrm{~h}$ after intracisternal injection of pneumococci. These observations are of particular interest because of the importance of increased blood flow in the development of vasogenic cerebral edema (5) and the importance of edema to the pathology of bacterial meningitis $(6,7)$.

The present report represents an extension of preliminary observations of pial arteriolar dilation after topical application

Received July 31, 1991; accepted January 22, 1992.

Correspondence: M. Douglas Jones, Jr., M.D., The Children's Hospital B065, 1056 E. Nineteenth Ave., Denver, CO 80218.

Supported in part by The Hospital for Consumptives of Maryland (Eudowood). of group B streptococci to the cerebral cortex of the rat (3). We have also tested the hypothesis that oxygen free radicals play an important role in the pathogenesis of this phenomenon.

\section{MATERIALS AND METHODS}

Animal studies were performed according to protocols approved by the Animal Care and Use Committee of the Johns Hopkins University School of Medicine. Male Sprague-Dawley rats (200-250 g) (Charles River Laboratories, Inc., Wilmington, MA) were anesthetized with thiopental, $100 \mathrm{mg} / \mathrm{kg}$, administered intraperitoneally. Rectal temperature was maintained at $38^{\circ} \mathrm{C}$ throughout the experiment with a servo-controlled heating pad. A tracheostomy was performed, and the left femoral artery and vein were cannulated to monitor blood pressure, obtain blood samples, and administer drugs. The animals were then paralyzed with i.v. gallamine, $25 \mathrm{mg} / \mathrm{kg}$, and ventilated with a rodent ventilator (Harvard Apparatus Co., Inc., S. Natick, MA). The fractional inspired oxygen concentration, respiratory rate, and tidal volume were adjusted to obtain stable arterial blood gases.

Cranial window. Cranial windows were constructed according to methods described by Morii et al. (8) with minor modifications. Briefly, the cranium was secured in a stereotaxic frame and the skull was exposed by incising and reflecting the skin and periosteum overlying the sagittal suture. Polyethylene tubes (PE50) for superfusion of artificial CSF and measurement of intracranial pressure were secured to the skull within a ribbon of dental acrylic placed around a $5 \times 7 \mathrm{~mm}$ rectangular area on the left parietal bone. Within the area enclosed by the acrylic, a craniotomy was performed with a power drill under an operative microscope. The bone flap was removed, and the dura was incised with microscissors and reflected. Bleeding from the dural edge was controlled by crushing individual vessels with microforceps. Artificial CSF $\left(\mathrm{Na}^{+} 156.5 \mathrm{mmol} / \mathrm{L}, \mathrm{K}^{+} 2.95 \mathrm{mmol} / \mathrm{L}\right.$, $\mathrm{Ca}^{2+} 2.50 \mathrm{mmol} / \mathrm{L}, \mathrm{Mg}^{2+} 1.33 \mathrm{mmol} / \mathrm{L}, \mathrm{Cl}^{-} 138.7 \mathrm{mmol} / \mathrm{L}$, $\mathrm{HCO}_{3}{ }^{-} 24.6 \mathrm{mmol} / \mathrm{L}$, dextrose $66.5 \mathrm{mg} / \mathrm{dL}$, urea $40.2 \mathrm{mg} / \mathrm{dL}$ ) (8) was aerated with $5 \% \mathrm{CO}_{2}, 7.5 \% \mathrm{O}_{2}$, and $87.5 \% \mathrm{~N}_{2}$ at $38^{\circ} \mathrm{C}$ and superfused over the exposed brain surface. A glass coverslip $(12 \mathrm{~mm})$ was placed on the dental acrylic and the window was sealed with more dental acrylic. After a 0.5 -h stabilization period, the intracranial pressure was set at $3 \mathrm{~cm} \mathrm{H}_{2} \mathrm{O}$ by adjusting the height of the exit catheter.

Microscope and video system. Pial vessels were visualized with an Olympus binocular microscope (model BHMJ; Olympus Corp., Lake Success, NY). Illumination was provided by a highintensity illuminator equipped with a flexible fiberoptic light source (Fiber-Lite, series 180; Dolan-Jenner Industries, Inc., Woburn, MA). A video camera (Ikegami television camera model ITC-410, type T; Ikegami Tsushinki Co., Ltd., Tokyo, Japan) was attached to the microscope to provide a video image displayed on a high-resolution monitor (Panasonic color video data monitor CT-1400MG; Panasonic Industrial Co., Secaucus, 
$\mathrm{NJ}$ ) and recorded on a Panasonic video cassette recorder (model NV-8950). This system provided magnification of $145 \times$, using $2.5 \times$ and $10 \times$ objective lenses. Fields of view on the video monitor were $1440 \times 1920 \mu \mathrm{m}$ and $500 \times 670 \mu \mathrm{m}$, respectively. Measurements of selected pial vessels were made directly from the video monitor.

Bacteria. Group B streptococci, type III (ATCC number 31475) from an infant with meningitis were obtained from the American Type Culture Collection, Rockville, MD. The evening before an experiment, freeze-dried bacteria were placed in modified Todd-Hewitt broth and grown overnight at $37^{\circ} \mathrm{C}$. The next morning, the bacterial suspension was diluted with artificial CSF immediately before instillation under the cranial window.

Protocol. The general protocol was the same in each experimental group. After a $1 / 2$-h stabilization period, artificial CSF or one of the test solutions was introduced under the window through a catheter and all catheters were clamped, creating a completely closed window. Rectal temperature, heart rate, and mean arterial blood pressure were measured every $1 / 2 \mathrm{~h}$ along with a 20 -s video recording of the pial vessels. Arterioles selected for measurement ranged in size from 20 to $113 \mu \mathrm{m}[52 \pm 23 \mu \mathrm{m}$ $( \pm$ SD)]. In most animals, two vessels could be identified in the window; in some only one and in others three could be seen. In each case, measurements were averaged for each animal. Thus, each animal is represented by a single measurement. Arterial blood gases were measured at time 0 and regularly thereafter. The rats were given supplemental doses of thiopental and gallamine as required to maintain anesthesia and paralysis; need for additional drugs was determined by corneal reflexes and variations in blood pressure and heart rate.

Bacterial concentration, bacterial viability, and bacteria-free growth medium. For these experiments, five animals were exposed to bacteria in a concentration of $10^{3}$ organisms $/ \mathrm{mL}$ and nine were exposed to a concentration of $10^{5}$ organisms $/ \mathrm{mL}$. Bacterial concentrations were determined by quantitative culture. The effects of heat-killed bacteria were studied in five animals and the effects of filtered growth media were studied in another five animals. For the experiments with filtered growth media, broth that had been inoculated the previous night was filtered through a $0.22-\mu \mathrm{m}$ filter (Millex-GS $0.22-\mu \mathrm{m}$ filter unit; Millipore Corp., Bedford, MA) to exclude bacteria. For experiments with heat-killed bacteria, a suspension of bacteria was killed by placing the vial in a boiling water bath for $5 \mathrm{~min}$. Absence of viable bacteria in the filtrate and the heat-treated material was confirmed by culture. Heat-killed organisms at a concentration of $10^{5}$ bacterial $/ \mathrm{mL}$ were then infused. Control animals for these experiments consisted of nine animals in which artificial CSF alone was infused under the window.

CSF $p H$. To determine effects of CSF $\mathrm{pH}$, five control animals were exposed to artificial CSF for a 3 -h period. The pial vessel diameters and vital signs were measured every $1 / 2 \mathrm{~h}$, and arterial blood gases were measured at hourly intervals. After $3 \mathrm{~h}$ of observation, acidic CSF ( $\mathrm{pH}=7.1$ ) was infused under the window. Pial arteriolar diameter was measured again after $10 \mathrm{~min}$. Acid CSF was then replaced with alkaline $\operatorname{CSF}(\mathrm{pH}=7.8)$, and the measurements were repeated after another $10 \mathrm{~min}$. These measurements were compared with data from five experimental animals exposed to group B streptococci for $3 \mathrm{~h}$. At the end of the 3-h period, alkaline CSF ( $\mathrm{pH}=7.8$ ) was infused under the window and pial arteriolar diameter was measured after $10 \mathrm{~min}$.

Oxygen free radical scavengers. PEG-SOD (Sigma Chemical Co., St. Louis, MO) and PEG-catalase (Sigma Chemical Co.) were given i.v. immediately after placement of the femoral venous catheter, approximately $1 \mathrm{~h}$ before infusion of test solutions into the cranial window, to three experimental groups. To insure that PEG-SOD and PEG-catalase had no independent effect, six animals were treated with PEG-SOD $(10000 \mathrm{U} / \mathrm{kg})$ and PEG-catalase $(20000 \mathrm{U} / \mathrm{kg})$ and then observed for $3 \mathrm{~h}$ after infusion of artificial CSF under the window. Three additional groups were used to study the effects of PEG-SOD and PEG- catalase on vasodilation associated with group B streptococci. The first was a group of untreated subjects exposed to group B streptococci. We studied three animals concurrently with studies of free radical scavengers. Because these studies confirmed observations in the six animals exposed to group B streptococci in the above investigations of $\mathrm{CSF} \mathrm{pH}$, no further experiments were performed; the nine untreated, bacteria-exposed animals were pooled for purposes of statistical analysis. A second group of four animals was pretreated with low doses of PEG-SOD $(500 \mathrm{U} / \mathrm{kg})$ and PEG-catalase $(8000 \mathrm{U} / \mathrm{kg})$, and a third group of four animals was pretreated with high doses $(10000$ and $20000 \mathrm{U} / \mathrm{kg}$, respectively). Doses were varied by dilution with saline. In each group, group B streptococci were infused under the window as described above, and physiologic measurements and measurements of vessel diameter were made over a 3-h period.

Statistics. Mean values and SD were calculated for all data. Statistical comparisons within groups were made using $t$ tests or repeated measures analysis of variance as appropriate. Multiple comparisons were analyzed with the Bonferroni correction or the Newman-Keuls test. Differences associated with $p<0.05$ were considered significant.

\section{RESULTS}

Initial experiments assessed the effects of group B streptococci over a 4-h period. We compared 14 experimental animals exposed to group B streptococci with nine control rats. Arterial $\mathrm{PO}_{2}, \mathrm{PCO}_{2}$, and mean arterial blood pressure were not statistically different between the two groups and were stable throughout the experiment. In nine control animals, there was no change in the diameter of pial arterioles during $4 \mathrm{~h}$ of observation (Fig. 1). We studied the effects of live group B streptococci at two different concentrations, $10^{3}$ and $10^{5}$ bacteria/mL; actual concentrations were $1.43 \times 10^{3}$ and $1.21 \times 10^{5}$ at time 0 and $7.10 \times 10^{3}$ and $5.88 \times 10^{5}$ at $4 \mathrm{~h}$. The degree of vasodilation was not affected by the bacterial concentration over this range. After $4 \mathrm{~h}$, arteriolar diameter had increased to $158 \pm 15$ (SD)\% of the baseline value in the five animals exposed to $10^{3}$ organisms $/ \mathrm{mL}$ and to $161 \pm$ $16 \%$ of the baseline value in the nine animals exposed to $10^{5}$ organisms/mL (Fig. 1). Dilation was progressive over time (Fig. 2) and was significantly different from control at $2.5 \mathrm{~h}$.

Effect of heat-treatment and filtration. Pial arterioles in another five animals were exposed to heat-killed bacteria at a concentration of $10^{5}$ bacteria/mL. Vital signs and arterial blood gases were not significantly different from control. Vasodilation at $4 \mathrm{~h}$ was similar to that seen with live organisms (Fig. 3).

To determine if the effects were due to a filterable substance, we passed cultures of group B streptococci $\left(10^{5}\right.$ organisms $\left./ \mathrm{mL}\right)$ through $0.22-\mu \mathrm{m}$ filters to exclude bacteria. Bacterial exclusion was confirmed by culture. We then infused the filtrate under the

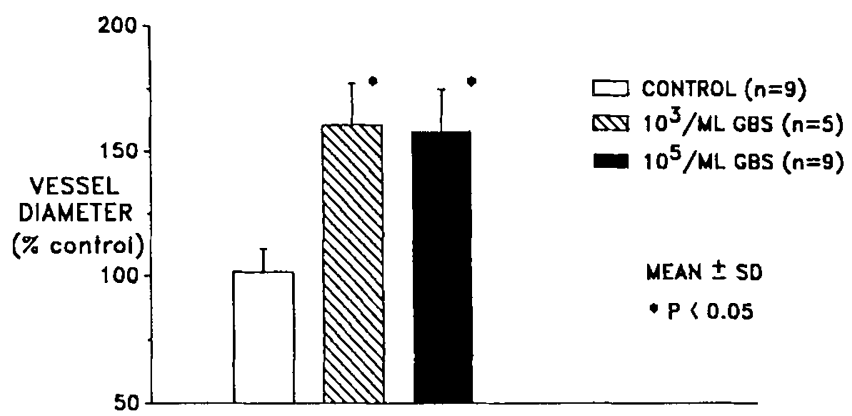

Fig. 1. Effect of concentration of group B streptococci on diameter of pial arterioles. Experimental animals were exposed to $1.43 \times 10^{3}$ and $1.21 \times 10^{5}$ bacteria/mL, respectively. Control animals were exposed to artificial CSF. Pial artery diameters are compared at $4 \mathrm{~h}$. Asterisks identify measurements significantly different from values in control subjects under the same conditions. Differences were identified using unpaired $t$ tests with the Bonferroni correction for multiple comparisons. 


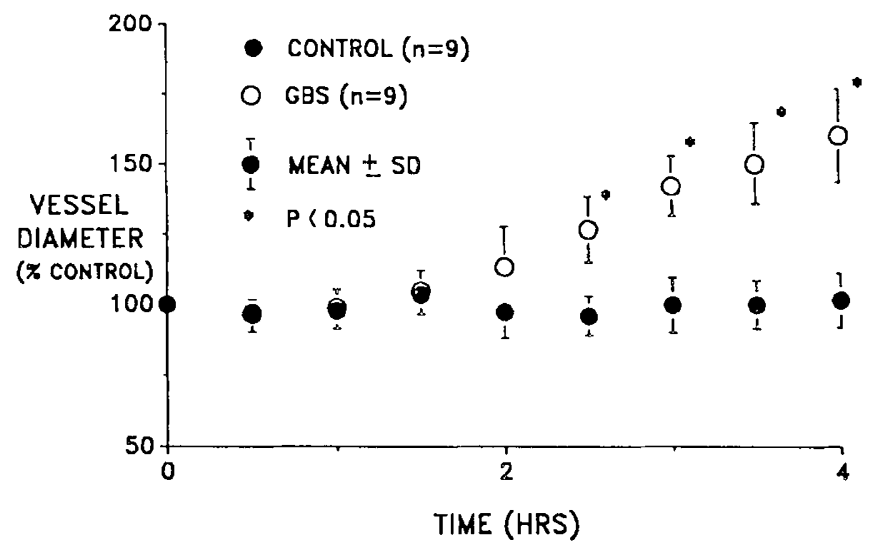

Fig. 2. Effect of group B streptococci on diameter of pial arterioles. Pial vessels in control animals were exposed to artificial CSF only, whereas vessels in experimental animals were exposed to live group $B$ streptococci $\left(1.21 \times 10^{5}\right.$ bacteria $\left./ \mathrm{mL}\right)$. Differences were identified with repeated measures analysis of variance and the Newman-Keuls test.

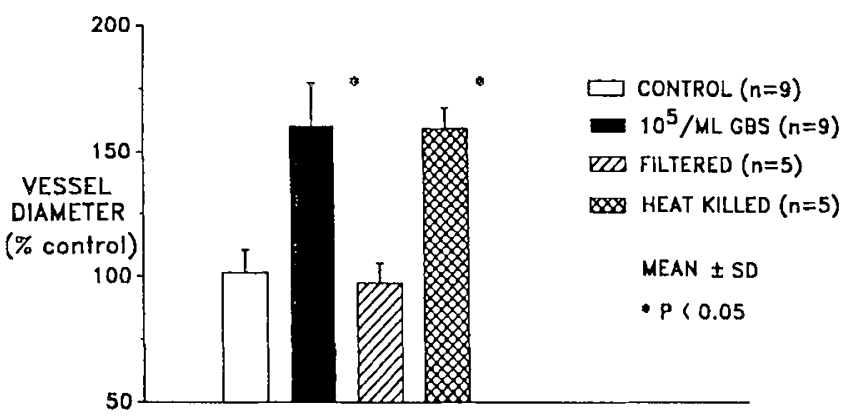

Fig. 3. Effect of heat-killed group B streptococci and filtrate of growth medium on diameter of pial arterioles. Data from original control and group B streptococci $\left(10^{5}\right.$ organism $\left./ \mathrm{mL}\right)$ groups are compared with subjects exposed to the same concentration of heat-killed bacteria and with subjects exposed to bacteria-free filtrate of growth media (obtained by passing a suspension of $10^{5}$ organisms $/ \mathrm{mL}$ of group B streptococci through a $0.22-\mu \mathrm{m}$ filter). Statistical analysis as in Figure 1.

window according to the above protocol. The filtrate had no effect on pial arteriolar diameter (Fig. 3).

CSF $p H$. To determine if the effects were due to changes in $\mathrm{CSF} \mathrm{pH}$, we exposed pial vessels in five control and six group $\mathrm{B}$ streptococci-exposed animals to alkaline $(\mathrm{pH}=7.8) \mathrm{CSF}$. In control animals, infusion of acidic CSF $(\mathrm{pH}=7.1)$ into the cranial window at the end of a 3-h observation period was associated with significant pial arteriolar dilation (to $135 \pm 23 \%$ of control; $p<0.05$ ); this was promptly reversed (to $101 \pm 10 \%$ of control) by infusion of alkaline CSF. Exposure of pial arterioles in five experimental animals to live group B streptococci for $3 \mathrm{~h}$ produced similar dilation (to $148 \pm 6 \%$ of control; $p<0.05$ ). However, there was no change in diameter after infusion of alkaline CSF.

Oxygen free radical scavengers. In preliminary studies, we infused a solution of nitroblue tetrazolium into the window at the end of a 3-h exposure to group B streptococci. The solution promptly took on the dark blue color characteristic of reduction, implying the presence of superoxide radicals (data not shown). We therefore studied three groups of animals pretreated with PEG-SOD and PEG-catalase.

Data for these studies are summarized in Figure 4. A group of six animals was pretreated with $10000 \mathrm{U} / \mathrm{kg}$ of PEG-SOD and $20000 \mathrm{U} / \mathrm{kg}$ of PEG-catalase followed by infusion of artificial CSF only into the window. No significant change in arteriolar diameter was found during $3 \mathrm{~h}$ of observation. Arterioles in four animals pretreated with PEG-SOD at a dose of $500 \mathrm{U} / \mathrm{kg}$ and PEG-catalase at a dose of $8000 \mathrm{U} / \mathrm{kg}$ followed by bacteria

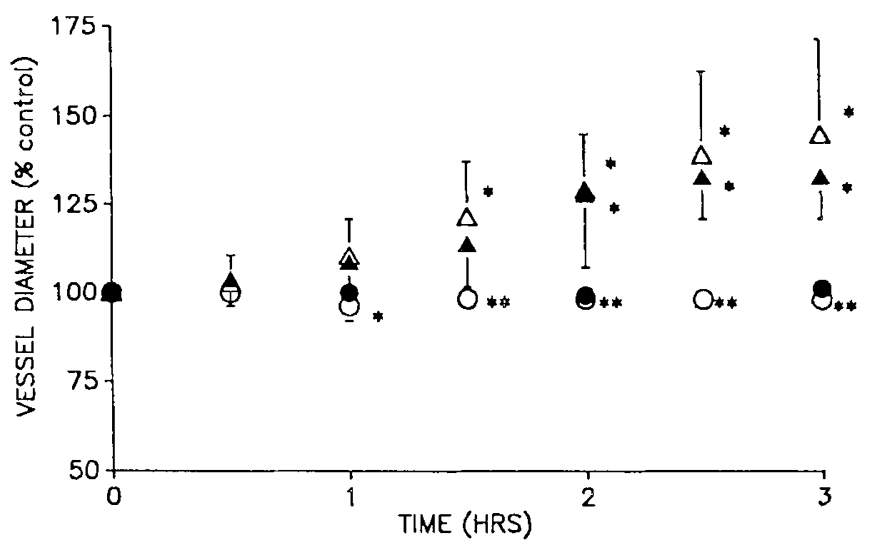

Fig. 4. Effect of pretreatment with PEG-SOD and PEG-catalase. Intravenous administration of PEG-SOD $(10000 \mathrm{U} / \mathrm{kg})$ and PEG-catalase $(20000 \mathrm{U} / \mathrm{kg})$ approximately $1 \mathrm{~h}$ before infusion of artificial CSF under the cranial window. $\mathbf{\Delta}$, Pretreatment with PEG-SOD $(500 \mathrm{U} / \mathrm{kg}$ ) and PEG-catalase $(8000 \mathrm{U} / \mathrm{kg})$ followed by infusion of group B streptococci under the cranial window. $O$, Pretreatment with PEG-SOD $(10000 \mathrm{U} / \mathrm{kg})$ and PEG-catalase $(20000 \mathrm{U} / \mathrm{kg})$ followed by infusion of group B streptococci. $\triangle$. Infusion of group B streptococci alone, without pretreatment with oxygen free radical scavengers. Data analysis as for Figure 2. *. Different from time $0(p<0.05)$. ${ }^{* *}$, Different from group exposed to group B streptococci but not pretreated with SOD and catalase.

prepared and infused according to the above protocol showed progressive dilation to $133 \pm 12 \%$ of control at $3 \mathrm{~h}$; dilation was significant after $2 \mathrm{~h}$. This was accompanied by less nitroblue tetrazolium reduction, assessed subjectively. In contrast, arterioles in four animals pretreated with PEG-SOD at a dose of $10000 \mathrm{U} / \mathrm{kg}$ and PEG-catalase at a dose of $20000 \mathrm{U} / \mathrm{kg}$ showed no dilation; indeed, slight but significant constriction $(96 \pm 4 \%$ of control) was seen at $1 \mathrm{~h}$. Still less nitroblue tetrazolium reduction was noted at $3 \mathrm{~h}$. These data were compared with a group of nine animals exposed to group B streptococci but not pretreated with PEG-SOD or PEG-catalase. This group consisted of the six animals reported above as part of the study of the effect of CSF pH together with an additional three animals done concurrently with studies of radical scavengers. Pooled data on this untreated group showed progressive dilation to $142 \pm 28 \%$ of control at $3 \mathrm{~h}$. These data are similar to those in the nine animals studied over $4 \mathrm{~h}$ (Fig. 2).

Statistical comparison of the four groups (the three SOD and catalase-treated groups and the untreated group) showed that the group pretreated with the higher doses of SOD and catalase was significantly different from the untreated group at $90 \mathrm{~min}$ and from the low-dose group at $2 \mathrm{~h}$. The group pretreated with lower doses was not significantly different from the untreated group.

\section{DISCUSSION}

The major findings of this study are as follows: 1) Exposure to either live group B streptococci at concentrations of $10^{3}-10^{5}$ organisms $/ \mathrm{mL}$ or killed organisms at $10^{5}$ organisms $/ \mathrm{mL}$, the range of concentrations encountered in meningitis (9), produces progressive dilation of pial arterioles. A bacteria-free filtrate was without effect. 2) Vasodilation was not reversed by infusion of alkaline CSF. 3) Vasodilation was eliminated by pretreatment with i.v. PEG-SOD and PEG-catalase in doses of 10000 and $20000 \mathrm{U} / \mathrm{kg}$, respectively.

The group B streptococcus is the most common cause of neonatal meningitis and a significant contributor to neonatal morbidity and mortality (10). Despite prompt antimicrobial therapy and supportive care, infection is fatal up to $60 \%$ of the time (11). As many as one half of survivors have complications ranging from language delays (12) to mental retardation, seizures, 
cortical blindness, and quadriparesis $(12,13)$. Despite the high morbidity, little is known about the pathogenesis of neurologic injury in group B streptococcal meningitis.

The present study, although performed in adult rather than newborn animals, represents an initial attempt to identify effects of group B streptococcus on cerebral arteries. Except for large extracranial arteries, the arterial bed is often surrounded by inflammation $(1,2)$. Together, the large intracranial arteries and the surface, or pial, arterioles account for approximately $70 \%$ of the brain's vascular resistance (see 14 for references). Pial arterioles alone constitute approximately $20 \%$ of the resistance, and because $30 \%$ of cerebral vascular resistance resides in passive capillaries and veins, pial arterioles constitute approximately $30 \%$ of the changeable vascular resistance. Dilation similar to that reported here, even if confined to pial arterioles, would be expected, because of the 4 th power relationship between vascular resistance and vessel diameter (14), to produce a $30 \%$ increase in cerebral blood flow.

The state of pial arterioles in meningitis has not been specifically studied, but the postmortem surface of the brain is often intensely hyperemic $(1,2,15)$. This impression is supported by recent in vivo data documenting an early increase in cortical blood flow in experimental meningitis (4) and by the present study. It would seem to be contradicted by data showing normal or low cerebral blood flow in humans and subhuman primates with meningitis. Paulson et al. (16) found that cerebral blood flow was normal in meningococcal meningitis and low in pneumococcal meningitis, and Smith et al. (15) reported decreased flow to forebrain in infant monkeys with Haemophilus influenzae meningitis. In addition, Tureen et al. (17) found no change in cerebral blood flow 16-20 h after intracisternal injection of Streptococcus pneumoniae.

There are several possible explanations for these discrepancies. The latter studies were done $16 \mathrm{~h}$ to several days into the course of the disease, when intracranial pressure is likely to have been increased by cerebral edema. Increased intracranial pressure may have been moderate, but even moderate increases in intracranial pressure will decrease cerebral blood flow if cerebral autoregulation is impaired in meningitis (17; Berkowitz ID, Hayden WR, Traystman RJ, Jones Jr MD, unpublished manuscript). On the other hand, it is possible that cortical blood flow was indeed increased (4) but that the techniques for measurement of blood flow in whole brain used in the latter studies may not have been sufficiently sensitive to detect increases in blood flow localized to cerebral cortex.

The present study provides evidence that vasodilation of pial arterioles begins soon after application of group B streptococci to the surface of the brain in concentrations of $10^{3}-10^{5}$ organisms/mL. Dilation was progressive and could not be attributed to CSF acidosis $(18,19)$. It is unlikely that the alkaline CSF used in our experiments was insufficient to change perivascular $\mathrm{pH}$. We infused several $\mathrm{mL}$ of fluid, and a similar procedure in vessels experimentally dilated with acid CSF caused prompt constriction.

Failure of arterioles to constrict with exposure to alkaline CSF implies not only that vasodilation was not due to acidosis, but also that the vessels were dysfunctional. Responsivity to changes in $\mathrm{pH}$ is a fundamental property of cerebral arterioles and underlies their response to $\mathrm{CO}_{2}$ (19). Further support for the hypothesis that the arterioles are dysfunctional is found in data from our laboratory as well as data recently published by Tureen et al. (17). The experiments from our laboratory (Berkowitz ID, Hayden WR, Traystman RJ, Jones Jr MD, unpublished manuscript) used $H$. influenzae in a model otherwise identical to that in the present report. We found that pial arterioles exposed to $H$. influenzae for $4 \mathrm{~h}$ failed to dilate appropriately to hemorrhagic hypotension. Tureen et al. (17) found that meningitis induced by intracisternal injection of pneumococci in a rabbit model was associated with failure of cerebral autoregulation, i.e. failure of cerebral vessels to respond to alterations in systemic blood pres- sure with appropriate reciprocal changes in cerebrovascular resistance.

Similar patterns of cerebral arteriolar dysfunction (sustained dilation and abnormal vasoreactivity) have been seen after acute hypertension and concussive head injury $(20,21)$. Kontos and coworkers (20-23) have implicated oxygen free radicals in this lesion. Furthermore, our studies showing vasodilation after infusion of heat-killed bacteria but no effect after infusion of a filtrate of the growth medium suggested that vasodilation was not the result of active elaboration of a soluble toxin. We therefore investigated the possibility that vascular injury was the result of oxygen free radicals associated with the inflammatory process.

In preliminary studies, we used nitroblue tetrazolium to indicate the presence of oxygen free radicals (22). In contrast to results in control animals, the nitroblue tetrazolium solution infused under the cranial window in animals exposed to group B streptococci showed prompt reduction. Oxygen free radicals were further implicated by the demonstration that pretreatment with adequate doses of PEG-SOD and PEG-catalase prevented arteriolar dilation. Our results are consistent with data recently published by Pfister et al. (4) showing that hyperemia in the cerebral cortex in experimental meningitis is eliminated by pretreatment with SOD.

Although these studies do not point to a source for oxygen free radicals, leukocytes are obvious candidates. The proposal that leukocyte infiltration may be deleterious in meningitis is not a new one $(6,7)$. Petersdorf and Luttrell $(23)$ reported that irradiation improved survival by almost $50 \%$ with experimental pneumococcal meningitis. Pathologic examination of brains from irradiated animals showed less meningeal inflammation than controls. Subsequent investigations have supported the suggestion that less meningeal inflammation is associated with improved survival (24). It also appears that neutropenia may protect against brain edema in both bacterial and chemical meningitis (25).

Release of oxygen free radicals is not the only way in which leukocytes might damage the cerebral vasculature $(6,7,26)$. Although we cannot rule out an independent role for other compounds $(6,7,26,27)$, our data support the proposition that vasodilation either resulted directly from oxygen free radicals or was the result of a sequence of events in which oxygen free radicals played an important intermediate role.

If the inflammatory process is the critical element in producing vascular damage in our model, it is interesting that killed bacteria were just as deleterious as live organisms. Tuomanen et al. (28) found that heat-killed, unencapsulated $S$. pneumoniae or purified cell wall from the same organisms produced inflammation equivalent to that of live organisms. Our data support the hypothesis that a heat-stable component, perhaps the cell wall, is important to production of inflammation by the group B streptococcus as well.

Acknowledgments. The authors thank Maria Lourdes Burbelo for her technical assistance and Karen Lingerman for her secretarial assistance.

\section{REFERENCES}

1. Adams RD, Kubik CS, Bonner FJ 1948 The clinical and pathological aspects of influenzal meningitis. Arch Pediatr 65:354-376

2. Berman PH, Banker BO 1966 Neonatal meningitis: a clinical and pathological study of 29 cases. Pediatrics 38:6-24

3. Keyes WG, Hudak ML, Jones Jr MD 1988 Effect of group B streptococci (GBS) on meningeal vessels. Pediatr Res 23:474A(abstr)

4. Pfister H-W, Koedel U, Haberl RL, Dirnagl U, Feiden W, Ruckdeschel G, Einhäupl KM 1990 Microvascular changes during the early phase of experimental bacterial meningitis. J Cereb Blood Flow Metab 10:914-922

5. Wahl M, Unterberg A, Baethmann A, Schilling L 1988 Mediators of bloodbrain barrier dysfunction and formation of vasogenic brain edema. $J$ Cereb Blood Flow Metab 8:621-634

6. Tunkel AR, Wispelwey B. Scheld WM 1990 Bacterial meningitis: recen advances in pathophysiology and treatment. Ann Int Med 112:610-623 
7. Sáez-Llorens X, Ramilo O, Mustafa MM, Mertsola J, McCracken Jr GH 1990 Molecular pathophysiology of bacterial meningitis: current concepts and therapeutic implications. J Pediatr 116:671-684

8. Morii S, Ngai AC, Winn HR 1986 Reactivity of rat pial arterioles and venules to adenosine and carbon dioxide: with detailed description of the closed cranial window technique in rats. J Cereb Blood Flow Metab 6:34-41

9. Feldman WE 1977 Relations of concentrations of bacteria and bacterial antigen in cerebrospinal fluid to prognosis in patients with bacterial meningitis. $\mathrm{N}$ Engl J Med 296:433-435

10. Baker CJ, Edwards MS 1990 Group B streptococcal infections. In: Remington JS, Klein JO (eds) Infectious Diseases of the Fetus and Newborn Infant. WB Saunders, Philadelphia, pp 742-811

11. Baker CJ, Barrett FF, Gordon RC, Yow MD 1973 Suppurative meningitis due to streptococci of Lancefield group B: a study of 33 infants. J Pediatr 82:724729

12. Edwards MS, Rench MA, Haffar AAM, Murphy MA, Desmond MM, Baker CJ 1985 Long-term sequelae of group B streptococcal meningitis in infants. J Pediatr 106:717-722

13. Chin KC, Fitzhardinge PM 1985 Sequelae of early-onset group B hemolytic streptococcal neonatal meningitis. J Pediatr 106:819-822

14. Hudak ML, Jones Jr MD, Popel AS, Koehler RC, Traystman RJ, Zegar SL 1989 Hemodilution causes size-dependent constriction of pial arterioles in the cat. Am J Physiol 257:H912-H917

15. Smith AL, Haas JE, Roberts MC, Stull TL, Mendelman PM 1985 Mechanisms of Haemophilus influenzae meningitis. In: Sande MA, Smith AL, Root RK (eds) Bacterial Meningitis. Churchill Livingstone, New York, pp 11-21

16. Paulson OB, Brodersen P, Hansen EL, Kristensen HS 1974 Regional cerebral blood flow, cerebral metabolic rate of oxygen, and cerebrospinal fluid acidbase variables in patients with acute meningitis and with acute encephalitis. Acta Med Scand 196:191-198
17. Tureen JH, Dworkin RJ, Kennedy SL, Sachdeva M, Sande MA 1990 Loss of cerebrovascular autoregulation in experimental meningitis in rabbits. J Clin Invest 85:577-581

18. Andersen NEO, Gyring J, Hansen AJ, Laurson H. Siesjö BK 1989 Brain acidosis in experimental pneumococcal meningitis. $\mathrm{J}$ Cereb Blood Flow Metab 9:381-387

19. Kontos HA, Raper AJ, Patterson Jr JL 1977 Analysis of vasoactivity of local $\mathrm{pH}, \mathrm{PCO}_{2}$ and bicarbonate on pial vessels. Stroke 8:358-360

20. Kontos HA, Wei E, Dietrich WD, Navari RM, Povlischock JT, Ghatak NR, Ellis EF, Patterson Jr JL 1981 Mechanism of cerebral arteriolar abnormalities after acute hypertension. Am 3 Physiol 240:H511-H527

21. Wei E, Kontos HA, Dietrich WD, Povlischock JT, Ellis EF 1981 Inhibition by free radical scavengers and by cyclooxygenase inhibitors of pial arteriola abnormalities from concussive brain injury in cats. Circ Res 48:95-103

22. Kontos HA 1985 Oxygen radicals in cerebral vascular injury. Circ Res 57:508516

23. Petersdorf RG, Luttrell CN 1962 Studies on the pathogenesis of meningitis. I. Intrathecal infection. $J$ Clin Invest 41:311-319

24. McAllister CK, O’Donoghue JM, Beaty HN 1975 Experimental pneumococcal meningitis. Il. Characterization and quantitation of the inflammatory process. J Infect Dis 132:355-360

25. Täuber MG, Borschberg U, Sande MA 1988 Influence of granulocytes on brain edema, intracranial pressure, and cerebrospinal fluid concentration of lactate and protein in experimental meningitis. J Infect Dis 157:456-464

26. Smedly LA, Tonnesen MG, Sandhaus BA, Haslett C, Guthrie LA, Johnston Jr RB, Henson PM, Worthen GS 1986 Neutrophil-mediated injury to endothelial cells. J Clin Invest 77:1233-1243

27. Weiss SJ 1989 Tissue destruction by neutrophils. N Engl J Med 320:365-376

28. Tuomanen E, Tomasz A, Hengstler B, Zak O 1985 The relative role of bacteria cell wall and capsule in the induction of inflammation in pneumococcal meningitis. J Infect Dis 151:535-540 